\begin{tabular}{|c|c|c|c|c|c|c|c|c|c|c|}
\hline \multirow{2}{*}{\multicolumn{3}{|c|}{ Demographic, clinical, and laboratory findings at diagnosis }} & \multicolumn{3}{|c|}{$\begin{array}{l}\text { arly-remission } \\
n=41\end{array}$} & \multicolumn{4}{|c|}{$\begin{array}{l}\text { Long-therapy } \\
\qquad \mathrm{n}=21\end{array}$} & \multirow[b]{2}{*}{$p$} \\
\hline & & & & & & & & & & \\
\hline Woman & $n(\%)$ & 20 & ( & 48.8 & ) & 12 & ( & 57.1 & ) & 0.5 \\
\hline Age: years & mean (SD) & 74.2 & ( & 7.8 & ) & 73.7 & ( & 5.8 & ) & 0.8 \\
\hline Body weight, kg & mean (SD) & 55.3 & ( & 11.18 & ) & 52.1 & ( & 9.23 & ) & 0.3 \\
\hline Body mass index, kg/m² & mean (SD) & 22.7 & ( & 4.03 & ) & 20.7 & ( & 3.10 & ) & 0.06 \\
\hline Fever & $\mathrm{n}(\%)$ & 10 & ( & 24.4 & ) & 7 & ( & 33.3 & ) & 0.5 \\
\hline Body weight loss & $n(\%)$ & 13 & ( & 31.7 & ) & 10 & ( & 47.6 & ) & 0.2 \\
\hline Peripheral edema & $n(\%)$ & 16 & ( & 39.0 & ) & 10 & ( & 47.6 & ) & 0.3 \\
\hline Serum C-reactive protein, $\mathrm{mg} / \mathrm{dL}$ & mean (SD) & 6.4 & 1 & 4.17 & ) & 8.8 & ( & 4.06 & ) & 0.03 \\
\hline Serum albumin, $\mathrm{mg} / \mathrm{dL}$ & mean $(S D)$ & 3.2 & ( & 0.47 & ) & 3.2 & ( & 0.57 & ) & 0.7 \\
\hline \multicolumn{11}{|l|}{ Treatment and clinical course } \\
\hline Starting dose of PSL: mg/day & mean (SD) & 12.6 & ( & 4.09 & ) & 14.5 & ( & 3.94 & ) & 0.1 \\
\hline $\mathrm{mg} / \mathrm{kg} / \mathrm{day}$ & mean (SD) & 0.24 & ( & 0.084 & ) & 0.28 & ( & 0.079 & ) & 0.1 \\
\hline Mean duration of GC treatment & month (SD) & 14.2 & 1 & 4.59 & ) & 43.4 & ( & 21.98 & ) & $<0.01$ \\
\hline Achieving remission & $\mathrm{n}(\%)$ & 41 & ( & 100 & ) & 9 & ( & 42.9 & ) & \\
\hline Relapse: times & mean (SD) & 0.4 & ( & 0.70 & ) & 3.1 & ( & 2.06 & ) & $<0.01$ \\
\hline Relapse till 6 months & $n(\%)$ & 3 & ( & 7.3 & ) & 8 & ( & 38.1 & ) & $<0.01$ \\
\hline
\end{tabular}

Disclosure of Interests: None declared

DOI: 10.1136/annrheumdis-2020-eular.796

\section{THU0294 THE DIFFERENCES IN THE CLINICAL SPECTRUM OF CRYOGLOBULINEMIC VASCULITIS BETWEEN SJÖGREN'S SYNDROME AND HCV HEPATITIS}

O. Argyropoulou ${ }^{1}$, V. Pezoulas ${ }^{2}$, L. Quartuccio ${ }^{3}$, F. Ferro ${ }^{4}$, S. Gandolfo ${ }^{3}$, V. Donati ${ }^{4}$, A. Venetsanopoulou ${ }^{1}$, L. Chatzis ${ }^{1}$, E. Zampeli ${ }^{5}$, M. Mavromati ${ }^{5}$, P. Voulgari ${ }^{6}$, C. Mavragani ${ }^{1}$, C. Baldini ${ }^{4}$, F. Skopouli ${ }^{5}$, D. Fotiadis ${ }^{2}$, M. Galli ${ }^{7}$, S. De Vita ${ }^{3}$, H. M. Moutsopoulos ${ }^{5}$, A. Goules ${ }^{1}$, A. Tzioufas ${ }^{1}$. ${ }^{1}$ Pathophysiology Department, Athens School of Medicine, National and Kapodistrian University of Athens, Athens, Greece; ${ }^{2}$ Unit of Medical Technology and Intelligent Information Systems, University of loannina, Ioannina, Greece; ${ }^{3}$ Rheumatology Clinic, Department of Medical Area, University of Udine, Udine, Italy; ${ }^{4}$ Rheumatology Unit, Department of Clinical and Experimental Medicine, University of Pisa, Pisa, Italy; ${ }^{5}$ Department of Nutrition and Clinical Dietetics, Harokopio University of Athens, Athens, Greece; ${ }^{6}$ Rheumatology Clinic, Department of Internal Medicine, Medical School, University of loannina, Ioannina, Greece; ${ }^{7}$ Infectious Disease Clinic, Ospedale Sacco, University of Milan, Milan, Italy

Background: Cryoglobulinemic vasculitis (CV) is a serious complication of Sjögren's syndrome (SS) and is closely associated with type II IgMk cryoglobulins. CV has been well documented in HCV patients without SS, and shares common features with CV in SS. So far, few studies have described the clinical picture of $\mathrm{CV}$ in HCV negative SS, but the number of studied patients was rather small and $\mathrm{CV}$ was not well defined. To better describe the clinical spectrum of $\mathrm{CV}$ in SS and explore the differences compared to HCV-related CV, a large cohort of well characterized patients is required.

Objectives: To study the clinical phenotype of CV in HCV-negative SS patients, in a large cohort of well characterized patients, after applying stringent classification CV criteria and in comparison with the classical CV of HCV patients.

Methods: From a total cohort of 1997 consecutive SS patients who fulfill the 2016 EULAR/ACR criteria and are followed up in 5 clinical centers ([Universities of Udine, Pisa and Athens, Harokopio and Ioannina, (UPAHI)], those who fulfil the 2011 classification criteria for $\mathrm{CV}$ were identified and compared with matched HCV-CV patients according to age and gender. Glandular, extra-glandular manifestations and serologic features were compared between the $2 \mathrm{CV}$ groups. Statistical analysis for categorical variables was performed by Fisher exact or chi-square tests and for continuous variables with $t$ test or Mann-Whitney accordingly.

Results: Among the 1083 SS patients who have been evaluated for cryoglobulins, $114(9,8 \%)$ were found positive. Seventy-one $(6,5 \%)$ SS patients met the 2011 CV criteria while 44 patients presented with type II IgMk cryoglobulinemia without CV. Sixty nine of $71(97 \%)$ SS related CV patients were females and 2 of $71(3 \%)$ males. Forty eight of $71(68 \%)$ had SS disease onset $>35$ and $<65$ years old while $14 / 71(19,7 \%)$ and $9 / 71(12,7 \%)$ had SS disease onset $<35$ and $>65$ years old respectively. The most common clinical manifestations of CV among SS patients were purpura $(90 \%)$ followed by arthralgias $(70 \%)$, fatigue $(59 \%)$, Raynaud's phenomenon (48\%), lymphadenopathy (31\%), peripheral neuropathy $(22,3 \%)$, vasculitic ulcer $(11,3 \%)$ and glomerulonephritis $(11,3 \%)$. Interestingly, almost $50 \%$ of SS related CV patients developed lymphoma and displayed high frequency of strong predictors including purpura, low C4 complement (88,6\%) and salivary gland enlargement (SGE). Compared to HCV-CV patients, SS-CV patients had higher frequency of sicca manifestations, SGE, fatigue, arthritis, Raynaud's phenomenon, lymphadenopathy, type II IgMk cryoglobulins and lymphoma.

Conclusion: The prevalence of cryoglobulinemia and CV among SS patients is about $10 \%$ and $6-7 \%$ respectively. SS-CV patients are mainly middle-aged females with purpura as the main clinical manifestation, and up to one half of them may develop lymphoma, which is rarer in HCV-CV. Compared to HCV-CV patients, SS patients with CV have more frequently sicca symptoms, SGE and type II IgMk cryoglobulins.

Disclosure of Interests: Ourania Argyropoulou: None declared, Vasileios Pezoulas: None declared, Luca Quartuccio: None declared, Francesco Ferro: None declared, Saviana Gandolfo: None declared, Valentina Donati: None declared, Aliki Venetsanopoulou: None declared, Loukas Chatzis: None declared, Evangelia Zampeli: None declared, Maria Mavromati: None declared, Paraskevi Voulgari: None declared, Clio Mavragani: None declared, Chiara Baldini: None declared, Fotini Skopouli: None declared, Dimitris Fotiadis: None declared, Massimo Galli: None declared, Salvatore De Vita Consultant of: Roche, Human Genome Science, Glaxo Smith Kline and Novartis, Haralampos M. Moutsopoulos: None declared, Andreas Goules: None declared, Athanasios Tzioufas: None declared

DOI: 10.1136/annrheumdis-2020-eular.4233

\section{THU0295 LOW IMMUNOGENICITY IN PATIENTS WITH GIANT CELL ARTERITIS TREATED WITH TOCILIZUMAB: 3-YEAR RESULTS FROM THE RANDOMIZED CONTROLLED PORTION AND OPEN-LABEL FOLLOW-UP OF A PHASE 3 TRIAL}

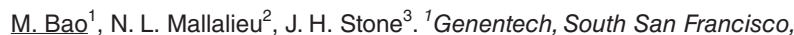
United States of America; ${ }^{2}$ Roche Innovation Center, New York, United States of America; ${ }^{3}$ Massachusetts General Hospital Rheumatology Unit, Harvard Medical School, Boston, United States of America

Background: Tocilizumab (TCZ) has low immunogenicity in patients with rheumatoid arthritis. ${ }^{1}$ The risk for immunogenicity remains to be determined in patients with giant cell arteritis (GCA) treated with TCZ. TCZ administered subcutaneously every week (QW) or every other week (Q2W) with 26-week prednisone tapering was superior to placebo $(\mathrm{PBO})$ plus 26 -week $(\mathrm{PBO}+26)$ or 52-week (PBO+52) prednisone tapering for the achievement of sustained remission in patients with GCA in the 52-week, double-blind part 1 of the GiACTA trial. ${ }^{2}$ Part 2 was a 2-year open-label, long-term follow-up in which patients were treated at the investigators' discretion; part 2 treatment could include initiation/termination of TCZ QW with or without glucocorticoids or methotrexate.

Objectives: To investigate immunogenicity of TCZ QW and Q2W regimens in patients with GCA in combination with a 26-week prednisone taper regimen versus $\mathrm{PBO}+26$ or $\mathrm{PBO}+52$ over the course of the GiACTA study in the randomized controlled part 1 and long-term follow-up part 2 .

Methods: In parts 1 and 2 combined, anti-TCZ antibodies (ADA) and corresponding pharmacokinetic $(\mathrm{PK})$ parameters were assessed in serum samples taken at scheduled times at weeks $0,8,24,36,52,76,100,136$, and 156 or at early withdrawal. Additional assessments were made for patients who interrupted blinded TCZ treatment for $\geq 4$ weeks in part 1 and those who withdrew from the study because of anaphylaxis/hypersensitivity. All samples were tested by screening assay, and samples that were ADA positive were further analyzed by a confirmation assay to verify specificity. If the confirmation assay was positive, 2 additional tests were performed to characterize the detected ADA: a neutralizing assay to test the neutralizing potential of ADAs and an assay to determine whether the detected ADA were of the IgE isotype. Proportions of patients in whom ADA developed were summarized for the safety population.

Results: Among evaluable patients (had baseline and $\geq 1$ postbaseline ADA assessments and received $\geq 1$ dose of study treatment) in part 1, ADA developed in 1 of $95(1.1 \%)$ and 3 of $46(6.5 \%)$ patients after TCZ QW and Q2W dosing, respectively. One of $49(2.0 \%)$ and 1 of $47(2.1 \%)$ in the PBO+26 and PBO+52 groups, respectively, tested positive for ADA but had not received TCZ and were considered false positives. In parts 1 and 2 combined, among 199 patients who received $\geq 1$ dose of TCZ, 193 (97\%) were evaluable (Table); TCZ-induced ADA developed in 13 of these patients $(6.7 \%)$ postbaseline (4 during part 1, 9 during part 2). Of these 13 patients, $8(4.1 \%)$ had ADA with neutralizing potential and 1 $(0.5 \%)$ had IgE ADA. Most TCZ-induced ADA were transient. There was no clear impact of TCZ-induced ADA on TCZ PK (Figure). No patients with TCZ-induced ADA experienced anaphylaxis, hypersensitivity reactions, or injection site reactions, and none withdrew because of lack of efficacy

Conclusion: In patients with GCA, treatment-induced ADA developed in a minority of patients and had no impact on TCZ PK, efficacy, or safety. The 